\title{
IMPLEMENTASI ACTIVE LEARNING DALAM PENINGKATAN MOTIVASI BELAJAR SISWA DI SMP NEGERI 1 JANGKAR
}

\author{
Oleh : \\ Abd. Aziz Noer \\ Fakultas Tarbiyah IAI Ibrahimy Situbondo \\ aziz.noer@gmail.com
}

\begin{abstract}
:
Learning process requires a professional teacher is carry out its duties, because to achieve success in the learning process is expect to master learning strategy, learning model and able to manage the class because students are different both in terms of catchment psychology of learning.

Active learning is a learning model that seeks to make active, creative, effective and enjoyable learning between teachers and students. In using active method of learning is needed expertise, both in terms expertise use of creative methods and classroom management. Because sometimes the reality in field is different from what has been prepared in active application of learning teachers must use multiple methods in accordance with taught material, and conducive management so that students are happy and not bored in receiving lessons.

Supporting factors and obstacles in improving learning motivation students are the supporting factors of PAI teacher competence, support from school principals both in terms of motivation and available facility as well as support from other teachers, and inhibiting factors lack of parental support for education. The solution to overcome obstacles is to establish good communication with guardian students such as meeting at a certain time for maximizing the school committee and always encourage students with strategies such as active learning that can make the spirit and motivated in learning.
\end{abstract}

Key Words: Aktive Learning, Motivasi Belajar Siswa.

\section{A. Pendahuluan}

Zaman yang semakin canggih dan berkembang akan memberikan apresiasi penting dalam dunia pendidikan. Pendidikan merupakan sarana yang menentukan perkembangan zaman di mana anak didik sangat membutuhkan suply keilmuan yang banyak dan baik dalam kehidupannya. Karen pendidikan tidak hanya dari sistem pembelajaran yang baik dan benar tetapi lebih dari itu. Hal demikian merupakan tantangan bagi 
seorang guru untuk terus meningkatkan kwalitas keilmuan dan kemampuannya dalam mewarnai dunia ini dengan sempurna.

UU Sisdiknas No. 20 /2003 bab 1 pasal 1 mengatakan pendidkan adalah usaha sadar dan terencana dalam mewujudkan suasana belajar proses pembelajaran agar peserta didik secara aktif mengembangkan potensinya sendiri untuk memiliki kekuatan sepiritual. ${ }^{1}$

Pendidikan akan berhasil dengan baik sesuai dengan tujuan yang telah ditetapkan jika berjalan kerjasama yang harmonis antara semua penanggung jawab. Maka tidak terlepas dari pendidik, peserta didik dan beberapa metode dan setrategi yang sangat dibutuhkan untuk memudahkan seorang ataupun siswa dalam proses pembelajaran.

Proses pembelajaran pada hakikatnya diarahkan untuk membelajarkan siswa agar dapat mencapai tujuan yang telah ditentukan. ${ }^{2}$ Kegiatan belajar mengajar adalah inti kegiatan dalam pendidikan. Segala sesuatu yang telah diprogramkan akan dilaksanakan dalam peroses belajar mengajar. Dalam KBM akan melibatkan semua komponen pengajaran, dan KBM akan menentukan sejauhmana telah diterapkan dapat dicapai.

Dalam KBM guru dan anak didik terlibat langsung dalam sebuah interaksi pembelajaran, sebagai perantaranya dalam interaksi belajar anak didiklah juga yang aktif, bukan hanya guru sebagai motifator dan fasilitator, Interaksi dalam belajar mengajar dikatakan maksimal apabila interaksi antara guru dengan semua anak didik dalam rangka mencapai tujuan yang telah ditetapkan bersama. ${ }^{3}$

Maka dari itu, untuk mengantisipasi kemungkinan gagalnya proses pembelajaran Pendidikan Agama Islam, guru harus mencari alternatif dalam memecahkan persoalan tersebut. Pendidik perlu mengetahui berbagai model belajar yang membahas bagaimana peserta didik bisa terhindar dari rasa bosan, dan terciptanya suasana belajar yang nyaman dan menyenangkan yang akhirnya akan memengaruhi kegiatan belajar peserta didik.

Belajar aktif ini merupakan sebuah kesatuan sumber kumpulan strategi-strategi pembelajaran yang komprehensif. Belajar aktif meliputi berbagai cara untuk membuat peserta didik aktif sejak awal melalui

1 UU. R.I. Nomor 20 Tahun 2013 Tentang Sisdiknas. (Bandung : Citra Umbara, 2010), hlm.2.

2 Wina Sanjaya, Perencanaan dan Desain dan Sistem Pembelajaran. (Jakarta: Kencana Prenada Media Group, 2008), hlm. 9.

3 Annisatul Mufarrokah, Strategi Belajar Mengajar, (Yogyakarta: Teras, 2009), h. 46.

128 JURNAL LISAN AL-HAL 
akvifitas-aktivitas yang membangun kerja kelompok dan dalam waktu singkat membuat mereka berfikir tentang materi pelajaran, juga terdapat teknik-teknik memimpin belajar bagi seluruh kelas, bagi kelompok kecil, merangsang diskusi dan debat, mempraktikkan keterampilanketerampilan, mendorong adanya pertanyaan-pertanyaan, bahkan membuat peserta didik dapat saling mengajar satu sama lain. sehingga kita tahu dalam proses belajar mengajar tidak hanya guru yang aktif, seakan akan siswa hanya menjadi pendengar setia saja.

Ada empat peranan aktif yang harus dimiliki oleh seorang guru guna untuk mencapai perubahan positif pada diri siswa yaitu:

a. Memantau kegiatan belajar siswa

b. Memberi umpan balik

c. Mengajukan pertanyaan-pertanyaan yang menantang

d. Mempertanyakan gagasan siswa ${ }^{4}$

Guru sangat dituntut tampil dalam mengajar, yang secara global meliputi perencanaan, pelaksanaan, dan evaluasi. Ia harus mampu menyusun setiap program, mulai dari memilih alat perlengkapan yang cocok, pembagian waktu yang tepat, metode mengajar yang sesuai, hingga seluruh kegiatan tersusun dengan baik. Sesuai dengan tujuan pendidikan nasional yaitu untuk mengembangkan potensi peserta didik agar menjadi manusia yang beriman dan bertaqwa kepada yang maha ESA, berakhlak mulia, sehat jasmani dan rohani. berilmu, cakap, kreatif, mandiri, sehingga pendidik dituntut untuk lebih meningkatkan kompetensinya pada upaya peningkatan aktifitas belajar siswa agar negara demokratis serta tanggung jawab. ${ }^{5}$

Perkembangan baru tentang pandangan belajar mengajar membawa konsekuensi kepada guru untuk meningkatkan peranan dan kompetensinya, karena proses belajar mengajar dan hasil belajar siswa ditentukan oleh peranan dan kompetensi guru. Guru yang kompeten akan mampu menciptakan lingkungan belajar yang efektif dan akan lebih mampu mengelola kelasnya sehingga hasil belajar siswa berada pada tingkat optimal. ${ }^{6}$

Peranan dan kompetensi guru dalam mengajar meliputi banyak hal, antara lain guru sebagai pengajar, pimpinan kelas, pembimbing, supervisor dan motivator. Pada diri siswa terdapat kekuatan mental yang

4 Jamal Ma'mur Asmanai, 7 Tips PAKEM, ( Jogjakarta: Diva Press, 2011), hlm. 92

5 Wiji Suwarno, Dasar-Dasar Ilmu Pendidikan, (Jogjakarta: Ar-Ruzz Media. 2006), Cet. 1

6 Uzer Usman, Menjadi Guru Profesional. (Remaja Rosda Kary. 2001). hlm. 20. 
menjadi penggerak belajar. Setiap individu mempunyai keinginan untuk belajar dan untuk bisa, yang disebut dengan minat. Proses pembelajaran tanpa didukung dengan adanya minat yang kuat maka proses tersebut dapat dikatakan tidak berhasil, sehingga terdapat tuntutan bagi seorang pendidik atau pembimbing belajar untuk menstimulir minat tersebut agar terealisasi dengan jalan belajar. Kekuatan mental yang berupa keinginan, perhatian, kemauan atau cita-cita. ${ }^{7}$

Ada tiga komponen utama dalam motivasi yaitu kebutuhan, dorongan, dan tujuan. Kebutuhan terjadi bila individu merasa ada ketidakseimbangan antara apa yang dia miliki dan yang ia harapkan. Dorongan merupakan kekuatan mental untuk melakukan kegiatan dalam rangka memenuhi harapan. Dorongan merupakan kekuatan mental yang berorientasi pada tujuan. Dorongan yang berorientasi pada pemenuhan harapan atau pencapaian tujuan. Tujuan adalah hal yang akan dicapai oleh seorang individu. Tujuan tersebut mengarahkan perilaku dalam hal ini perilaku belajar. Secara spikologi, tujuan merupakan titik akhir, sementara pencapaian adalah kebutuhan. Jika tujuan tercapai, maka kebutuhan terpenuhi untuk "sementara". Jika kebutuhan terpenuhi, maka orang akan menjadi puas, dan dorongan mental untuk berbuat "terhenti sementara". 8

\section{B. Pembahasan}

1. Implementsi active learning dalam peningkatan motivasi belajar PAI siswa SMPN I Jangkar

Guru merupakan salah satu faktor yang memiliki peranan yang segnifikan dalam menunjang keberhasilan dalam proses pembelajaran, hal ini dimaksudkan agar guru terus meningkatkatkan profesionalisme terkait dengan aktifitas guru dalam proses pembelajaran, seperti upaya mencari, memahami, menerapkan kemudian mengkaji ulang dari evaluasi yang dilakukan atas beberapa kesalhan yang di lakukan dalam menerapkan pembelajaran aktif .

Pembelajaran aktif tampaknya telah menjadi pilihan utama dala praktek pendidikan saat ini. Di Indonesia gerakan pembelajaran aktif ini terasa semakin mengemuka bersamaan dengan upaya mereformasi pendidikan nasional. Gerakan perubahan ini terus berlanjut sampai sekarang para guru terus menerus didorong untuk dapat menerapkan konsep pembelajaran aktif dalam setiap praktek pembelajaran untuk

7 Ibid. hlm. 11.

8 Muhibin Syah, Psikologi Belajar, (Bandung: PT. Logis Wacana Ilmu. 1998), hlm. 64.

$130 \mid$ JURNAL LISAN AL-HAL 
memotivasi siswa dalam belajar.

Beberapa kalangan berpendapat bahwa inti dari reformasi pendidikan ini justru terletak pada perubahan paradigma pembelajaran dari model pembelajaran pasif ke model pembelajaran aktif. Oleh karena itu, guru harus jeli dalam memilih metode. Sehingga metode yang digunakan sesuai dengan kondisi individu anak, karena merekalah yang akan belajar. Dan tentunya juga disesuaikan dengan materi yang akan disampaikan. Pada umumnya metode-metode yang di gunakan oleh guru PAI dalam penerapan metode Active Learning yaitu: jigsaw learning, card sort, the power of two, diskusi, dan lain sebagainya. Dan paling penting adalah pembelajaran berbasis masalah, karena mampu merangsang siswa untuk berfikir.

Seorang guru harus mampu menyajikan metode-metode yang menarik sehingga membuat siswa tidak merasa jenuh dan bosan dalam menerim pelajaran. Karena hal itu selalu membuat siswa aktif dalam kegiatan belajar, penggunaan permainan atau geme adalah salah satu cara untuk meningkatkan motivasi belajar siswa. Karena adanya permainan, konsentrasi yang semula jenuh, lelah, dan tidak terfokus pada pembelajaran akan menjadi fress dan tergugah untuk belajar, oleh karena itu setiap guru dalam mengajar harus menggunakan beberapa variasi atau metode yang menarik sehingga dalam proses belajar siswa tidak cepat bosan yang nantinya akan berakibat kepda mereka sehingga mereka tidak punya keinginan dalam belajar. Guru juga harus benar-benar matang dalam menyiapkan metode yang akan di pakai dalam penyampaian materi karena terkadang kenyataan di lapangan berbeda dengan apa yang sudah di siapkan semaksimal mungkin, berdoa, refleksi memperbaiki, jika sesuai dengan yang di rencanakan tetapi jika tidak di tinggalkan yang kemudian dijadikan bahan evaluasi untuk yang akan datang.

Active learning adalah segala bentuk pembelajaran yang memungkinkan siswa berperan secara aktif dalam proses pembelajaran itu sendiri baik dalam bentuk interaksi antar siswa maupun siswa dengan guru dalam proses pembelajaran.

Active learning pada dasarnya berusaha untuk memperkuat dan memperlancar stimulus dan merespon anak didik dalam pembelajaran, sehingga proses pembelajaran menjadi hal yang menyenangkan, tidak menjadi hal yang membosankan bagi mereka, dengan menerapkan penggabungan metode dalam strategi active learning dapat membantu ingatan mereka.

Apalagi jika yang digunakan hanya metode ceramah siswa tidak akan sepenuhnya merekam apa yang disampaikan oleh guru, mereka akan 
merasa bosan dan bahkan ada yang menganggap materi yang disampaikan itu adalah dongeng sebelum tidur, beda halnya jika menggunakan penggabungan metode seperti setelah penyampaian materi yang digunakan metode ceramah kemudian dipraktekkan oleh siswa akan lebih mudah paham dan lebih kuat merekam dalam ingatan mereka, sehingga mereka dapat dihantarkan kepada tujuan pembelajaran dengan sukses yang dapat dibuktikan dengan hasil atau nilai belajar.

Oleh karena itu agar belajar secara aktif guru perlu menggunakan strategi yang tepat sehingga peserta didik mempunyai motivasi yang tinggi untuk belajar. Dan perlu di ingat setiap sesuatu yang baru pada biasanya akan menimbulkan perbedaan yang baru pula, dan pada biasanya respon dari siswa semakin semangat dan sangat tertarik dengan materi yang diajarkan guru.

Pembelajaran yang menggunakan strategi Active Learning sangat berpengaruh terhadap siswa, mereka akan semakin termotivasi dalam belajar, merasa senang dan nyaman mengikuti proses pembelajaran, mereka diberi suguhan tidak hanya berupa teori namun disertai praktik yang memudahkan pemahaman mereka.

Stimulus yang diberikan kepada siswa melalui peserta didik melalaui actve learning yang digunakan dalam pembelajaran akan menimbulkan respon yang baik dan dapat memperlancar hubungan antara stimulus dan respon, sehingga respon yang ditimbulkan semakin kuat, hal ini akan memberi kesan yang kuat pula pada diri anak didik. Sehingga mereka akan mampu mempertahankan respon tersebut dalam ingatannya, respon yang menyenangkan yang ditimbulkan stimulus akan memberi kesan yang mendalam pada diri anak didik, sehingga meraka cenderung akan mengulang aktifitas tersebut. Akibat dari hal ini adalah anak didik mampu mempertahankan stimulus dalam memori meraka dalam waktu yang lama. sehingga mereka mampu me-recall apa yang diproleh dalam pembelajaran tanpa mengalami hambatan apapun.

2. Faktor pendukung dan penghambat implementasi active learning dalam peningkatan motivasi siswa.

a. Adapun faktor pendukung di SMPN I Jangkar ialah:Faktor yang mendukung dalam implementasi active learning dalam peningkatan motivasi belajar siswa ialah kompetensi guru PAI, dukungan dari kepala sekolah yang mampu memberi motivasi-motivasi selaku pemimpin di sebuah lembaga pendidikan dan dukungan lainnya yang berupa fasilitas-fasilitas yang mendukung dalam proses pembelajaran seperti adanya LCD yang digunakan guru dalam proses 
pembelajaranyang sangat membantu karena dalam penggunaan LCD siswa lebih mudah mencerna dalam tanyangan motivasi yang di lakukan oleh guru. Dan juga fasilitas seperti Moshallah yang dijadikan praktek pembelajaran seperti praktek shalat berjamaah dan praktekpraktek lainnya dan juga dukungan guru-guru lain dalam memberikan motivasi ide-ide dalam proses pembelajaran.

b. Adapun faktor penghambat di SMPN I Jangkar ialah sebagai berikut: Setiap melangkah pasti ada salah yang mana kesalahan itu sebagai bahan evaluasi untuk membenahi diri, begitu juga yang di alami oleh seorang guru dalam peroses pembelajaran yang menggunakan strategi Active Learning pasti ditemukan sebuah kesalahan atau kelemahan meski hanya sedikit dalam mempraktekkannya, kendalakendala lainnya seperti faktor kurangnya dukungan dari orang tua yang manyoritas bukan dari keluarga yang berpendidikan, dan semangat belajar. Dan juga hasil dari observasi kami di SMPN I Jangkar dalam menggunakan LCD tidak selalu digunakan dalam mata pelajaran khususnya PAI akan tetapi penggunaan LCD hanya digunakan kadang-kadang saja karena persediaan LCD terbatas.

3. Solusi mengatasi faktor penghambat implementasi active learning dalam peningkatan motivasi siswa.

Solusi yang di gunakan dalam implementasi active learning di SMP Nengri 1 Jangkar dalam menghadapi kendala dalam peroses pembelajaran khususnya dalam pelajaran PAI dengan cara menjalin komonikasi yang baik terhadap wali murid seperti mengadakan pertemuan khusus kepada wali murid disaat tertentu seprti pada saat pelepasan siswa kelas akhir dan pada saat penerimaan raport yang disampaikan oleh masing-masing wali kelas dalam menyampaikan hal-hal yang berkaitan dengan proses pembelajaran disekolah dan tak lupa juga memberikan motivasi terhadap orang tua betapa pentingnya pendidikan itu dan memaksimalkan kinerja komite sekolah dan selalu mendorong dan menyemangati siswa dengan berbagai strategi pendidikan dan pendekatan sepeti strategi actve learning adalah pembelajaran yang aktif, menyenangkan dan juga pembelajaran yang banyak menggunakan praktek agar memudahkan siswa menyerapnya karena tanpa praktek akan sulit masuk dalam otak anak didik, oleh karena itu melalui strategi active learning siswa tidak hanya mendapatkan teori saja tapi praktek yang telah dipraktekkan disini akan lebih memudahkan mereka untuk menyerapnya. 


\section{Simpulan}

Implementasi actie learning dalam meningtkan motivasi belajar siswa di SMPN 1 Jangkar yaitu dengan implementasi beberapa metode pembelajaran aktif seperti metode ceramah, sosiodrama, demonstrasi, diskusi, tanya jawab, card sort, jigsaw learning, exsam questions writing, thinks pairshare, sehingga mampu memberikan dukungan terhadap siswa dan memotivasi siswa agar lebih aktif untuk belajar serta semangat mengikuti proses belajar dan juga dapat mengembangkan kreativitas siswa.

Faktor pendukung dan penghambat dalam peningkatan motivasi belajar siswa ialah: Faktor pendukung kompetensi guru PAI yaitu mendapatkan dukungan dari kepala sekolah baik dari segi motivasi dan fasilitas-fasilitas yang tersedia serta dukungan dari guru-guru yang lain. Faktor penghambatnya adalah kurangnya dukungan dari orang tua siswa terhadap pendidikan, semangat belajar dan dalam penggunaaan LCD yang terbatas.

Solusi yang dilakukan untuk mengatasi faktor penghambat ialah menjalin komonikasi yang baik terhadap walimurid mengadakan pertemuan khusus disaat tertentu, memaksimalkan komite sekolah dan selalu mendorong dan menyemangati siswa dengan strategi seperti active learnig yang dapat membuat semangat dan termotivasi dalam belajar.

\section{DAFTAR PUSTAKA}

Mufarrokah, Annisatul. Strategi Belajar Mengajar. Yogyakarta: Teras. 2009.

Bonwell, C.C., Actve learning: creating Exsetement in the class room. Center for tecting and learning, st. Louis college of pharmacy. (onlene) tersedia: http: // psych. Viug, edu, 1995.

Hamruni, Strategi Model-Model Pembelajaran Aktif Menyenangkan. Yogyakarta: Fakultas Tarbiyah UIN Sunan Kalijaga. 2009.

Hartono, strategi Pembelajaran Active Learning Tersedia. http: //sditalqalam. Wordpress. Com.

Asmani, Jamal Ma'mur. 7 Tips PAKEM. Jogjakarta: Diva Press. 2011.

Meliun L. Siberman. Acteve Learning 101 Strategi Pembelajaran Aktif. Yogyakarta: Pustaka Insan Madani

Hamid, Moh. Soleh. Metode Edu Tainmet. Jogjakarta. Diva Press. 2011.

Mohibbin Syah, Psikologi belajar. Bandung, PT. Logis Wacana ilmu. 1998.

Sardiman A. M, Interaksi dan Motivasi Belajar Mengajar. Jakarta: PT. Grafindo Persada. 2000.

$134 \mid$ JURNAL LISAN AL-HAL 
UU. RI. Nomor 20 Tahun 2003. Tentang Sikdisnas Citra Umbara. Bandung: 2010

Usman, Uzer. Menjadi Guru Profesional. Bandung: Remaja Rosda Karya. 2001.

Suwarno, Wiji. Dasar-Dasar Ilmu Pendidikan. Jogjakarta: Ar-Ruzz Media. 2006.

Sanjaya, Wina. Perencanaan dan Desain dan Sistem Pembelajaran. Jakarta: Kencana Prenada Media group. 2008. 
"Implementasi Aktif Learning"

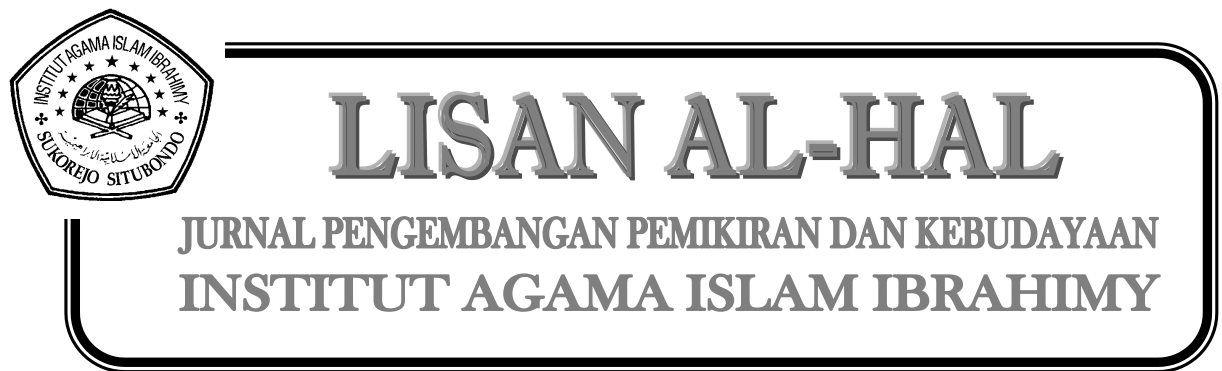

136 JURNAL LISAN AL-HAL 